\title{
Better Outcome of XELOX Chemotherapy in Patients with Advanced Intestinal-Type Adenocarcinoma of the Ampulla of Vater
}

\author{
Han Sang Kim, ${ }_{1}^{1}$ Sang Jun Shin, ${ }^{1}$ Joo-Hang Kim, ${ }^{1}$ Hyunki Kim ${ }^{2}$ and Hye Jin Choi ${ }^{1}$ \\ ${ }^{1}$ Division of Medical Oncology, Department of Internal Medicine, Yonsei University College of Medicine, Seoul, \\ Korea \\ ${ }^{2}$ Department of Pathology, Yonsei University College of Medicine, Seoul, Korea
}

\begin{abstract}
Adenocarcinoma arising from the ampulla of Vater is a rare disease and has limited data regarding outcome of chemotherapy. The ampulla of Vater is a heterogeneous junctional structure located at the union of the common bile duct, the pancreatic duct, and the small intestine. Thus, ampullary adenocarcinoma is classified as either intestinal type or pancreatobiliary type. We investigated the efficacy of the XELOX (capecitabine plus oxaliplatin) chemotherapy in patients with recurrent or metastatic ampullary adenocarcinoma, and analyzed the histopathologic features and outcomes. From November 2009 to December 2011, 21 patients were treated with XELOX regimen. XELOX was administered in outpatient clinic every 3 weeks according to the following protocol: oral administration of capecitabine 750 $\mathrm{mg} / \mathrm{m}^{2}$ twice a day on days $1-14$ and intravenous injection of oxaliplatin $130 \mathrm{mg} / \mathrm{m}^{2}$ on day 1 . With follow-up of median 16.6 months, median time to progression (TTP) was 7.6 months $(95 \%$ confidence interval $[\mathrm{Cl}$, 6.7-8.5), and median overall survival was 19.7 months (95\% Cl, 14.8-23.6). Two patients (9\%) achieved complete response and 6 patients $(29 \%)$ showed partial response. In subgroup analysis with tissue specimens obtained from 17 patients, median TTP was longer among patients with the intestinal-type adenocarcinoma $(n=7)$, compared to those with the pancreatobiliary type $(n=10)(13.1 \mathrm{vs.} 6.4$ months, $P$ $=0.038$ ). The most common grade 3-4 adverse event was neutropenia $(27 \%)$, and most events were mild. XELOX chemotherapy shows favorable efficacy with manageable toxicity for advanced intestinal-type ampullary adenocarcinoma.
\end{abstract}

Keywords: adenocarcinoma of the ampulla of Vater; capecitabine; intestinal; oxaliplatin; pancreatobiliary Tohoku J. Exp. Med., 2013 September, 231 (1),21-28. C 2013 Tohoku University Medical Press

\section{Introduction}

Ampullary adenocarcinoma (AAC), arising from the ampulla of Vater, is a rare neoplasm that accounts for approximately $0.2 \%$ of gastrointestinal cancers and $6 \%$ of periampullary cancers (Howe et al. 1998; Heinrich and Clavien 2010). About two-thirds of patients present with jaundice caused by obstruction of distal bile duct in earlystage disease. Curative surgery is possible in about $50 \%$ of patients with AAC, compared to $10 \%$ of pancreatic cancer (Monson et al. 1991; Romiti et al. 2012). Despite the high rate of radical surgery, about $50 \%$ of patients with AAC die from recurrent disease and 5-year survival rate ranges from $33 \%$ to $68 \%$ (de Castro et al. 2004; Woo et al. 2007; Lowe et al. 2009).
Currently, there is no consensus guideline for the AAC from the National Comprehensive Cancer Network (NCCN) or the European Society for Medical Oncology (ESMO). Limited data exist for treatment options in patients with recurrent or metastatic disease because most clinical trials included AAC as only small part of study population in pancreatic, biliary tract, or small bowel cancers. The phase III trial, which included patients with advanced biliary tract cancer, gemcitabine plus cisplatin showed better overall survival (OS) compared to gemcitabine monotherapy. However, only $5 \%$ patients had AAC and, therefore, cannot be a representative regimen for AAC (Valle et al. 2010). Recently, a retrospective study of cisplatin-based combination offered another possibility for AAC treatment, with the response rate of $27.5 \%$ and an OS of 12.5 months in 29

Received April 24, 2013; revised and accepted August 20, 2013. Published online August 31, 2013; doi: 10.1620/tjem.231.21.

Correspondence: Hyunki Kim, M.D., Ph.D., Department of Pathology, Yonsei University College of Medicine, 50 Yonsei-ro, Seodae-

mun-gu, Seoul 120-752, Korea.

e-mail: kimhyunki@yuhs.ac

Hye Jin Choi, M.D., Division of Oncology, Department of Internal Medicine, Yonsei University College of Medicine, 50 Yonsei-ro, Seodaemun-gu, Seoul 120-752, Korea.

e-mail: choihj@yuhs.ac 
patients (Kim et al. 2010).

Capecitabine plus oxaliplatin (XELOX) was originally developed as an effective first-line treatment for metastatic colorectal cancer (Cassidy et al. 2004). To date, various types of advanced gastrointestinal cancer have been treated with XELOX including esophagus (Jatoi et al. 2006), gastric (Kim et al. 2012) and small bowel cancer (Overman et al. 2009). Notably, a phase II study in 30 patients with small bowel and AAC suggested XELOX as a preferred regimen (Overman et al. 2009).

The ampulla of Vater is a heterogeneous junctional structure located at the union of the common bile duct, the pancreatic duct, and the small intestine. AAC is classified according to the epithelium of origin as either intestinal type or pancreatobiliary type (Kimura et al. 1994; Carter et al. 2008). The histologic features of intestinal-type adenocarcinoma are similar to those of colorectal adenocarcinoma. The tumor cells of intestinal type are columnar and have pseudostratified elongated nuclei. These tumor cells express cytokeratin 20 (CK20), mucin 2 (MUC2; intestinaltype mucin), and caudal type homeobox 2 (CDX2). Pancreatobiliary-type adenocarcinoma has a phenotype similar to that of pancreatic ductal adenocarcinoma. The tumor glands consist of cuboidal or columnar cells, usually without nuclear stratification, associated with more abundant desmoplastic stroma (Kimura et al. 1994; Fischer and Zhou 2004) and express cytokeratin 7 (CK7), mucin 1 (MUC1) and mucin 5AC (MUC5AC) (Chu et al. 2005; Westgaard et al. 2009).

Histopathologic type is an independent prognostic marker for resected AAC, and pancreatobiliary type exhibits a poor prognosis; the prognosis of the intestinal type resembles that of colorectal cancer (Carter et al. 2008; Westgaard et al. 2008). Moreover, molecular classification makes it possible to observe different biological behaviors and distinguish two subtypes of AAC based on immunohistochemistry (Zhou et al. 2004; Chu et al. 2005; Sessa et al. 2007; Amptoulach et al. 2011; Westgaard et al. 2013). Specially, the intestinal epithelial-specific marker, caudaltype homeodomain transcription factor 2 (CDX2) was an independent good prognostic marker for resected AAC (Hansel et al. 2005). Based on these studies, the pancreatobiliary type of AAC may be less responsive to XELOX than the intestinal type and immunohistochemistry indicators could be used as predictive markers.

Here, we report the efficacy of the XELOX regimen in patients with recurrent and/or metastatic AAC and compare efficacies of the regimen according to the histopathologic subtype based on morphologic and immunohistochemical evaluation.

\section{Patients and Methods}

Patients

Between January 2003 and December 2011, 67 patients received palliative chemotherapy for recurrent or metastatic AAC at the Severance Hospital, Seoul, Korea. The XELOX regimen (capecitabine in combination with oxaliplatin) was applied to total 21 patients. We collected patient characteristics including sex, age, performance status, histopathologic differentiation, extent of disease and any prior treatment (surgery, chemotherapy, or radiation). Medical information including toxicities, response and survival data were collected from the medical records. Response determined based on Response Evaluation Criteria in Solid Tumors (RECIST 1.0). Toxicity was graded based on the Common Terminology Criteria for Adverse Events v3.0 (CTCAE). This study was undertaken after obtaining approval by a local Human Investigations Ethical Committee.

\section{Treatment}

All patients were treated with oral administration of capecitabine $750 \mathrm{mg} / \mathrm{m}^{2}$ twice a day on days $1-14$ and intravenous injection of oxaliplatin $130 \mathrm{mg} / \mathrm{m}^{2}$ on day 1 , followed by a seven-day rest period. Treatments were administered in an outpatient clinic and repeated every 3 weeks.

\section{Immunohistochemistry}

The histologic features of the tumors were evaluated by a pathologist (H. Kim). The histopathologic classification of tumors was performed by combining the morphologic evaluation of the light microscopy and immunohistochemical study. On hematoxylin eosin (H-E) staining, the morphologic resemblance of the tumors to that of the colorectal adenocarcinoma or pancreatic ductal adenocarcinoma was evaluated. Then, to confirm the histologic classification, we performed an immunohistochemical study using three intestinal-type markers (CDX2, CK20, and MUC2) and three pancreatobiliary-type markers (CK7, MUC1, and MUC5AC).

Briefly, the representative $4 \mu \mathrm{m}$-thick sections were deparaffinized and rehydrated through a series of xylene and alcohol solutions. The endogenous peroxidase was blocked with $3 \%$ aqueous hydrogen peroxide. The slides were pretreated in a microwave oven for antigen retrieval. The sections were incubated with the primary antibodies \{MUC1 (BC-2, 1:100, Abcam, Cambridge, UK): MUC2 (Ccp58, 1:200, NovoCastra, Newcastle, UK), MUC5AC (CLH2, 1:100, NovoCastra), CK7 (OV-TL 12/30, 1:100, DAKO, Glostrup, Denmark), CK20 (Ks20.8, 1:100, DAKO), and CDX2 (DAK-CDX2, $1: 400, \mathrm{DAKO})\}$ for $1 \mathrm{~h}$ at room temperature and then overnight at $4^{\circ} \mathrm{C}$. The antibodies were detected using the avidin-biotin complex method, using diaminobenzidine as a chromogen. The cases with more than $10 \%$ immunoreactive tumor cells were categorized as "positive", and the cases with less than or equal to $10 \%$ immunoreactive tumor cells were categorized as "negative".

\section{Statistical analysis}

We analyzed TTP, OS and toxicity profiles of all patients in this study. TTP was defined as the time from the first day of chemotherapy to the date of disease progression and OS as the time from the first day of chemotherapy to death from any cause. The TTP was estimated by the Kaplan-Meier analysis. Subgroup analysis regarding TTP and ORR comparison between histopathologic types were estimated using the log-rank test and Fisher's exact test, respectively. All tests were two-sided, and a $p$-value $<0.05$ was considered statistically significant. Data were analyzed using SPSS software (version 18.0). 


\section{Results}

\section{Patient demographics}

A total of 21 patients were treated from November 2009 to December 2011. The baseline patient demographics are listed in Table 1. Eighteen patients were treated with XELOX as first-line treatment and three patients as secondline. Prior chemotherapy regimen for three patients was combination of gemcitabine and cisplatin. Eleven of the 21 patients were women, and the median age of all patients was 61 years (range, 30 to 77 years). Seventeen of the 21 patients were available for immunohistochemistry. On immunohistochemical study, ten patients were classified as pancreatobiliary-type which showed positive for MUC1, MUC5AC, or CK7; seven patients were classified as having intestinal-type AAC, which displayed positive results for CDX2, MUC2, or CK20 (Fig. 1, Table 2).

\section{Treatment delivery}

In all, 155 cycles of XELOX were administered (median, 7 cycles; range, 1 to 15), and the median duration of treatment was 21 weeks (range, 3 to 54 weeks). During chemotherapy, dose reductions and treatment delays were reported in $4(19 \%)$ patients and $8(38 \%)$ patients, respectively. The median cycle of dose reductions was cycle 4 (range, 2 to 6). Reasons for treatment discontinuation were disease progression $(n=11,52 \%)$, peripheral neuropathy ( $n$ $=3,14 \%)$ and patient refusal $(n=1,5 \%)$.

\section{Efficacy}

All 21 patients were analyzed (Table 3). Two (9\%) achieved complete response (CR) and $6(29 \%)$ had a partial response (PR), for an objective response rate (ORR) of $38 \%$. Eleven patients $(53 \%)$ reached stable disease (SD) status and median SD duration was 7.3 months (95\% CI, 6.4 to 8.2 months). After a median follow-up of 16.6 months, the median TTP was 7.6 months (95\% CI, 6.0-9.2 months)

Table 1. Patient characteristics.

\begin{tabular}{|c|c|c|}
\hline Characteristics & No. & $\%$ \\
\hline \multicolumn{3}{|l|}{ Age, years } \\
\hline Median (range) & \multicolumn{2}{|c|}{$61(30-77)$} \\
\hline \multicolumn{3}{|l|}{ Sex } \\
\hline Male & 10 & 48 \\
\hline Female & 11 & 52 \\
\hline \multicolumn{3}{|l|}{ ECOG performance status } \\
\hline 0 & 1 & 5 \\
\hline 1 & 19 & 90 \\
\hline 2 & 1 & 5 \\
\hline \multicolumn{3}{|l|}{ Differentiation } \\
\hline Well or moderately differentiated & 17 & 81 \\
\hline Poorly differentiated & 4 & 19 \\
\hline \multicolumn{3}{|l|}{ Disease status } \\
\hline Locally advanced & 0 & 0 \\
\hline Metastatic & 21 & 100 \\
\hline \multicolumn{3}{|l|}{ Site of metastiasis } \\
\hline Liver & 13 & 62 \\
\hline Lung & 5 & 24 \\
\hline Peritoneum & 6 & 29 \\
\hline Nodal, distant & 10 & 48 \\
\hline Adrenal gland & 1 & 5 \\
\hline Bone & 1 & 5 \\
\hline \multicolumn{3}{|l|}{ Prior treatment* } \\
\hline Surgery & 7 & 33 \\
\hline Surgery + adjuvant chemotherapy & 2 & 10 \\
\hline Surgery + adjuvant chemoradiation & 3 & 14 \\
\hline Radiation & 1 & 5 \\
\hline Radiation + chemotherapy & 1 & 5 \\
\hline
\end{tabular}

ECOG, Eastern Cooperative Oncology Group.

*For 14 patients with recurrent disease. 
(A) Intestinal type

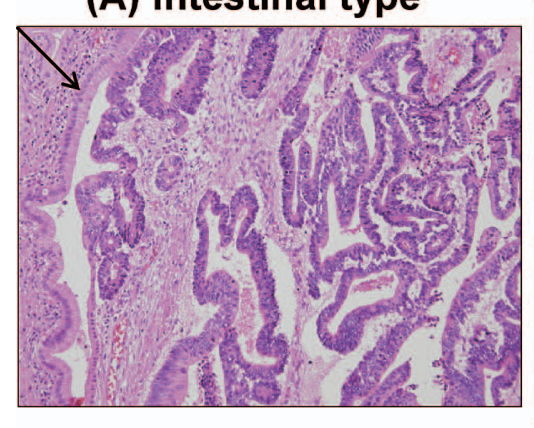

(B) Pancreatobiliary type

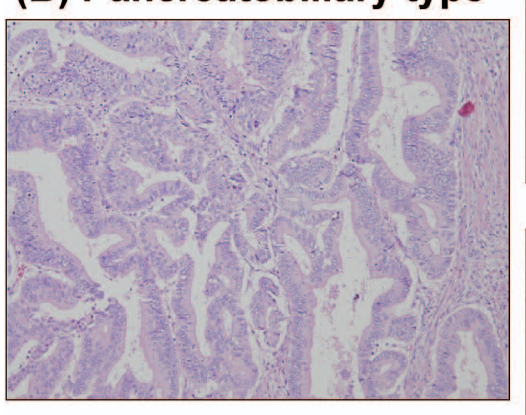

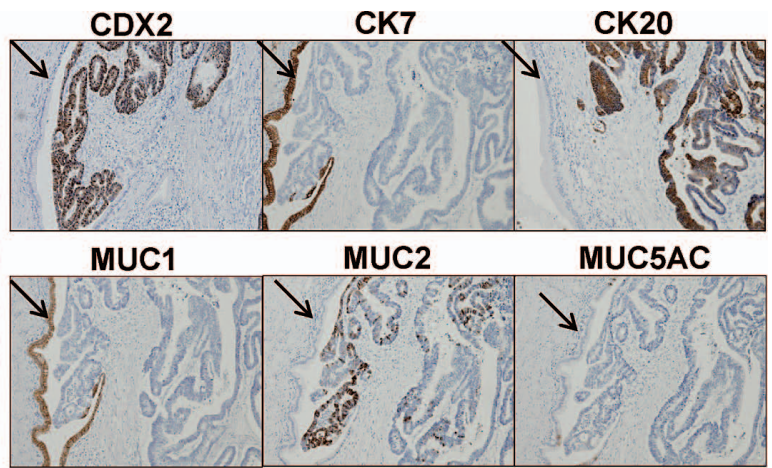

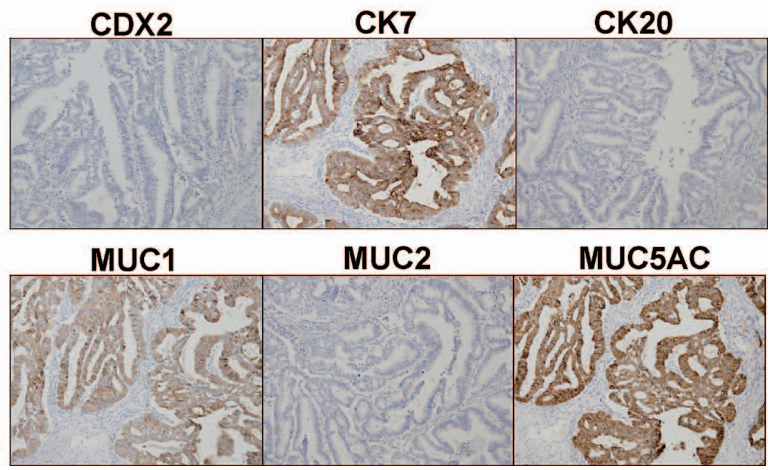

Fig. 1. Representative cases of the intestinal (patient No. 14) and the pancreatobiliary subtype (patient No. 16).

(A) The intestinal type adenocarcinoma in 50-year-old man. The histologic features which resemble those of colorectal adenocarcinoma are evident. The tumor glands are positive for CDX2, CK20 and MUC2 which are intestinal markers, and negative for CK7, MUC1 and MUC5AC which are pancreatobiliary markers. The arrows indicate the non-neoplastic ampulary epithelium as an internal control for the immunohistochemical stains. (B) Pancreatobiliary type adenocarcinoma in 60-year-old woman. The tumor glands are positive for CK7, MUC1 and MUC5AC, and negative for CDX2, CK20 and MUC2.

Table 2. Immunohistochemical results of 17 patients with available tissues.

\begin{tabular}{|c|c|c|c|c|c|c|c|c|}
\hline Patient No. & Sex/Age & MUC-1* & MUC-5AC* & $\mathrm{CK}-7 *$ & MUC-2** & CK- $20 * *$ & $\mathrm{CDX}-2 * *$ & Subtype \\
\hline$\# 1$ & $\mathrm{~F} / 70$ & - & - & - & - & + & + & intestinal \\
\hline$\# 2$ & $\mathrm{~F} / 53$ & + & - & - & - & - & - & pancreatobiliary \\
\hline \#3 & $\mathrm{F} / 62$ & + & + & + & - & - & - & pancreatobiliary \\
\hline$\# 4$ & $\mathrm{~F} / 71$ & - & + & - & - & - & + & pancreatobiliary \\
\hline$\# 5$ & $\mathrm{~F} / 56$ & + & + & - & - & - & - & pancreatobiliary \\
\hline \# 6 & $\mathrm{M} / 30$ & + & + & + & - & - & - & pancreatobiliary \\
\hline$\# 7$ & $\mathrm{M} / 70$ & + & - & - & - & - & - & pancreatobiliary \\
\hline$\# 8$ & $\mathrm{M} / 70$ & + & + & + & + & - & - & pancreatobiliary \\
\hline$\# 9$ & $\mathrm{M} / 47$ & + & - & + & + & ++ & - & intestinal \\
\hline$\# 10$ & $\mathrm{M} / 68$ & + & + & + & - & - & - & pancreatobiliary \\
\hline$\# 11$ & $\mathrm{~F} / 77$ & - & - & - & - & + & + & intestinal \\
\hline$\# 12$ & $\mathrm{M} / 70$ & + & - & - & - & + & + & intestinal \\
\hline$\# 13$ & $\mathrm{M} / 61$ & + & + & - & - & - & - & pancreatobiliary \\
\hline$\# 14$ & $\mathrm{M} / 51$ & - & - & - & + & + & + & intestinal \\
\hline$\# 15$ & $\mathrm{~F} / 60$ & - & - & - & + & + & + & intestinal \\
\hline$\# 16$ & $\mathrm{~F} / 46$ & + & + & + & - & - & - & pancreatobiliary \\
\hline$\# 17$ & $\mathrm{M} / 70$ & + & - & - & + & + & + & intestinal \\
\hline
\end{tabular}

M, male; F, female; MUC, mucin; CK, cytokeratin; CDX, caudal homeobox gene transcription factor.

*Markers for pancreatobiliary type, **Markers for intestinal type. 
Table 3. Tumor response to treatment.

\begin{tabular}{|c|c|c|c|c|}
\hline \multirow{2}{*}{ Response } & $\begin{array}{l}\text { All of patients } \\
\quad(n=21)^{*}\end{array}$ & $\begin{array}{l}\text { Intestinal type } \\
\qquad(n=7)\end{array}$ & \multicolumn{2}{|c|}{$\begin{array}{l}\text { Pancreatobiliary type } \\
\qquad(n=10)\end{array}$} \\
\hline & No. $\quad(\%)$ & No. $\quad(\%)$ & No. & $(\%)$ \\
\hline $\mathrm{CR}$ & $2 \quad(9)$ & $1 \quad(14)$ & 0 & \\
\hline PR & $6 \quad(29)$ & $3 \quad(43)$ & 2 & (20) \\
\hline SD & $11 \quad(53)$ & $3 \quad(43)$ & 7 & (70) \\
\hline PD & $2 \quad(9)$ & 0 & 1 & (10) \\
\hline ORR (CR +PR) & $8 \quad(38)$ & $4 \quad(57)$ & 2 & (20) \\
\hline Median TTP, months & $7.6 \quad(6.0-9.2)$ & $14.3 \quad(4.2-24.3)$ & 7.0 & $(2.5-11.5)$ \\
\hline
\end{tabular}

$\mathrm{CR}$, complete response; $\mathrm{PR}$, partial response; $\mathrm{SD}$, stabgle disease; $\mathrm{PD}$, progressive disease; ORR, objective response rate; TTP, time to progression.

*Four patients not available tissues for immunohistochemistry (one for CR, one for PR, one for SD and one for PD, respectively).

(A)

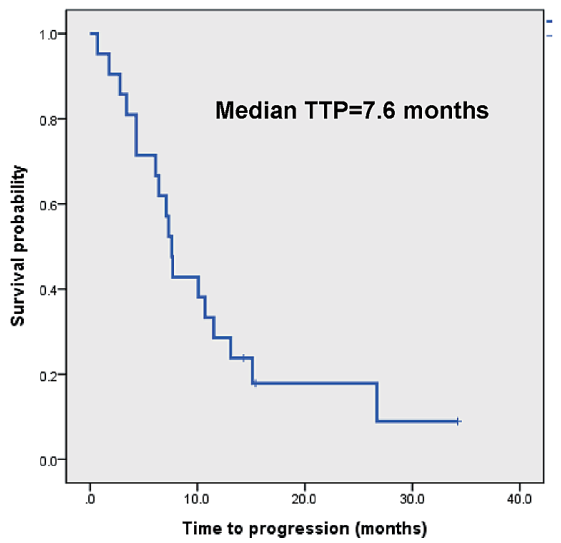

(C)
(B)

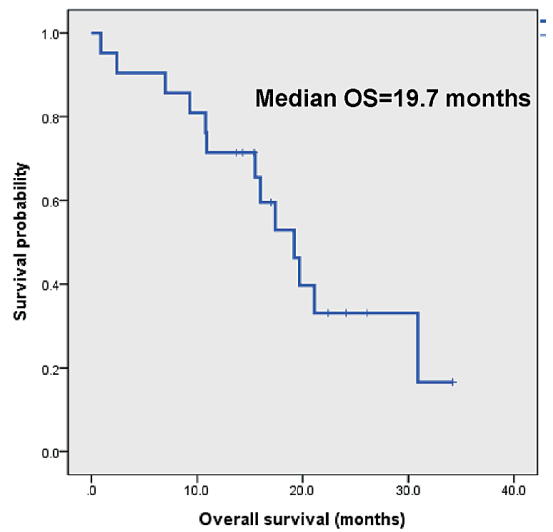

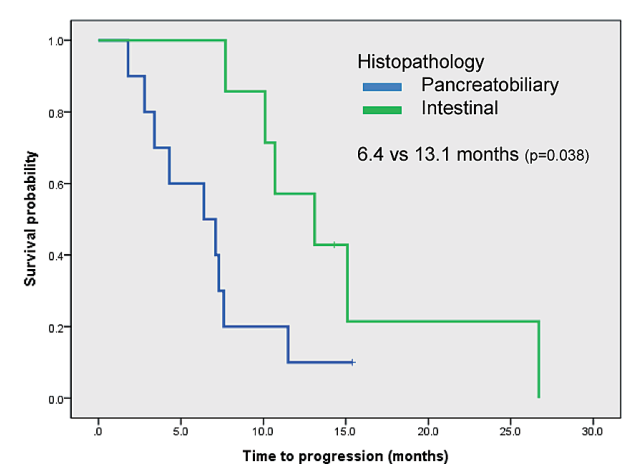

Fig. 2. Kaplan-Meier plots of time to progression and overall survival.

(A) time to progression, (B) overall survival and (C) time to progression of 17 patients according to histopathologic differentiation: intestinal $(n=7)$ and pancreatobiliary type $(n=10)$.

and median OS was 19.7 months (95\% CI, 14.8-23.6 months) (Fig. 2A, B).

In subgroup analysis according to histopathologic type (Fig. 2C), the median TTP was longer in patients with intestinal type AAC (13.1 months; 95\% CI, 6.9-19.2 months) compared to those with pancreatobiliary type AAC (6.4 months; 95\% CI, 2.1-10.7 months) $(P=0.038)$. XELOX also achieved higher ORR in patients with the intestinal type compared to the pancreatobiliary type, though the results were not statistically significant $(57 \%$ vs. $20 \%, P=$ $0.16)$.

\section{Toxicity}

Treatment-related toxicites are listed in Table 4. The 
H.S. Kim et al.

Table 4. Treatment-related adverse events during treatment.

\begin{tabular}{|c|c|c|c|c|c|c|}
\hline \multirow{2}{*}{ Toxicity } & \multicolumn{5}{|c|}{ Grade (No. of patients) } & \multirow{2}{*}{$\begin{array}{l}\text { Incidence of } \\
\geq \text { Grade } 3(\%)\end{array}$} \\
\hline & 1 & 2 & 3 & 4 & 5 & \\
\hline \multicolumn{7}{|l|}{ Hematologic } \\
\hline Neutropenia & 3 & 5 & 5 & 0 & 0 & 24 \\
\hline Febrile neutropenia & - & - & 0 & 0 & 0 & 0 \\
\hline Anemia & 3 & 3 & 0 & 0 & 0 & 0 \\
\hline Thrombocytopenia & 4 & 3 & 1 & 0 & 0 & 5 \\
\hline \multicolumn{7}{|l|}{ Non-hematologic } \\
\hline Fatigue & 4 & 8 & 1 & 0 & 0 & 5 \\
\hline Peripheral neuropathy & 2 & 8 & 2 & 0 & 0 & 9 \\
\hline Hand-foot syndrome & 3 & 3 & 0 & 0 & 0 & 0 \\
\hline Anorexia & 6 & 6 & 0 & 0 & 0 & 0 \\
\hline Nausea & 6 & 5 & 0 & 0 & 0 & 0 \\
\hline Vomiting & 2 & 3 & 1 & 0 & 0 & 5 \\
\hline Diarrhea & 1 & 2 & 0 & 0 & 0 & 0 \\
\hline Mucositis & 2 & 0 & 0 & 0 & 0 & 0 \\
\hline AST/ALT elevation & 3 & 1 & 1 & 0 & 0 & 5 \\
\hline Pain & 1 & 5 & 0 & 0 & 0 & 0 \\
\hline Bilirubin & 1 & 3 & 1 & 0 & 0 & 5 \\
\hline
\end{tabular}

AST, aspartate transaminase; ALT, alanine transaminase.

Table 5. Selected regimens from the studies including patients with ampullary adenocarcinoma.

\begin{tabular}{lccccc}
\hline \multicolumn{1}{c}{ Regimen } & $\begin{array}{c}\text { No. of patients } \\
\text { AAC/Total }(\%)\end{array}$ & $\begin{array}{c}\text { ORR } \\
(\%)\end{array}$ & $\begin{array}{c}\text { TTP or PFS } \\
\text { (months) }\end{array}$ & $\begin{array}{c}\text { OS } \\
(\mathrm{months})\end{array}$ \\
\hline Capecitabine/oxaliplatin & $12 / 30(40)$ & 50 & 9.8 & 20.4 & II (Overman et al. 2009) \\
Gemcitabine/cisplatin & $9 / 204(4)$ & 31 & 8.0 & 11.7 & III (Valle et al. 2010) \\
Gemcitabine/oxaliplatin & $2 / 33(6)$ & 36 & 5.7 & 15.4 & II (Andre et al. 2004) \\
Fluorouracil or gemcitabine/cisplatin & $29 / 29(100)$ & 28 & 4.9 & 12.5 & R (Kim et al. 2010) \\
Capecitabine/oxaliplatin & $21 / 21(100)$ & 38 & 7.6 & 19.7 & R \\
5-FU/doxorubicin/mitomycin C & $4 / 38(11)$ & 18 & 5.0 & 8.0 & II (Gibson et al. 2005) \\
5-FU/epirubicin/cisplatin & $6 / 27(22)$ & 19 & 5.2 & 9.0 & III (Rao et al. 2005) \\
Gemcitabine/oxaliplatin/erlotinib & $4 / 135(3)$ & 30 & 5.8 & 9.5 & III (Lee et al. 2012) \\
5-FU/epirubicin/gemcitabine/cisplatin & $7 / 37(19)$ & 43 & 7.9 & 12.1 & II (Cereda et al. 2010) \\
\hline
\end{tabular}

AAC, ampullary adenocarcinoma; ORR, objective response rate; TTP, time to progression; PFS, progression free survival; OS, overall survival; FU, fluorouracil; NR, not reached; R, retrospective study.

most common treatment-related grade 3-4 adverse event was neutropenia (5 patients, 24\%) without febrile event. Peripheral neuropathy ( 2 patients, 9\%) was the most frequent grade 3-4 non-hematologic toxicity. Other toxicities, including fatigue, anorexia, and nausea were primarily grade 1-2 and easily manageable. There was no difference in toxicity profiles between intestinal and pancreatobiliary type. There were no treatment-related deaths.

\section{Discussion}

Owing to rarity and heterogeneity of tissue of origin, there is no standard regimen and limited data suggest varied options for advanced AAC patients (Table 5). Overall, 5-FU derivative, platinum, and gemcitabine have been the cornerstone of combination chemotherapy of AAC, all of which have showed an ORR of nearly 30\% (range, 18 to 50 ) and median OS of approximately 12 months (range, 8.0 to 20.4) (Andre et al. 2004; Gibson et al. 2005; Rao et al. 2005; Overman et al. 2009; Cereda et al. 2010; Kim et al. 2010; Valle et al. 2010; Lee et al. 2012). Though no superior regimen exists that has been confirmed by randomized controlled study, XELOX is the most evaluated regimen to date in AAC and could be the preferred regimen, owing to the comparable efficacy and tolerance in a phase II and in our study (Overman et al. 2009).

There are several morphologic characteristics available in the classification of AAC subtype (Kimura et al. 1994; Fischer and Zhou 2004). However, it is difficult to classify 
$\mathrm{AAC}$ as either intestinal or pancreatobility type when based on morphologic features, especially if AAC were moderately to poorly differentiated. To overcome this difficulty and ambiguity of morphology-base classification, we used a panel of immunohistochemical markers for intestinal type (CDX2, MUC2, and CK20) and for pancreatobiliary markers (MUC1, MUC5AC, and CK7).

The molecular characteristics of AAC have been studied by including a KRAS mutation of $37 \%$ and microsatellite instability (MSI) rate of 10-20\% (Howe et al. 1997; Perrone et al. 2006; Ruemmele et al. 2009; Agaram et al. 2010). Considering our finding that clincal behavior is different between the intestinal and the pancreatobiliary type AAC, these molecular studies should be based on histopathologic type to determine therapeutic implications.

In this study, we observed different treatment outcome between the intestinal and the pancreatobiliary type of AAC with XELOX, which suggests the potential role of histopathologic classification as a predictive marker for XELOX. In addition, this study could allow patients to be assigned a proper chemotherapy regimen according to histopathology. XELOX may be the favored treatment for intestinal type AAC. In this study, 3 patients received gemcitabine plus cisplatin prior to XELOX. Of these, patients with intestinal-type AAC showed progression after only 3 months ( $n=$ $2)$, while the patient with pancreatobiliary type AAC experienced a TTP of 10 months $(n=1)$.

Targeted therapy in AAC is unknown area and requires further investigation. In case of intestinal-type AAC, targeted agents of colorectal cancer would guide the introduction new drugs. Currently, KRAS mutation is the only validated predictive marker for colorectal cancer to decide among the use of monoclonal antibody to epidermal growth factor receptor (EGFR), cetuximab and panitumumab for treatment (Cunningham et al. 2010). Bevacizumab prolonged progression free survival and OS when added to XELOX or fluoroucacil and oxliplatin in untreated metastatic colorectal cancer, which also encourages its use in intestinal-type AAC (Saltz et al. 2008).

This is the first study to analyze treatment outcomes according to histopathologic type. Our study showed the possibility of tailored chemotherapy regimen. Nevertheless, this study has several limitations. This was a retrospective study with a small number of patients. In addition, histopathologic classification was not done to all patients. Thus, clinical relevance as a predictive impact of histopathologic subtype needs to be interpreted cautiously. Better survival for patients with the intestinal type AAC can be attributed to both effectiveness of XELOX chemotherapy and favorable prognosis of the intestinal type.

In conclusion, capecitabine plus oxaliplatin is a feasible combination regimen for recurrent or metastatic AAC, with favorable efficacy and manageable toxicity in outpatient setting. The intestinal type showed better survival and further investigation for predictive marker are needed.

\section{Acknowledgements}

This study was supported by a faculty research grant for Yonsei University College of Medicine for 2009 (6-2009-0195 \& 6-2012-0044).

\section{Conflict of Interest}

The authors declare no conflict of interest.

\section{References}

Agaram, N.P., Shia, J., Tang, L.H. \& Klimstra, D.S. (2010) DNA mismatch repair deficiency in ampullary carcinoma: a morphologic and immunohistochemical study of 54 cases. Am. J. Clin. Pathol., 133, 772-780.

Amptoulach, S., Josefsson, A., Kavantzas, N. \& Kalaitzakis, E. (2011) Adenocarcinoma of the ampulla of Vater: does the histopathologic type matter? Scand. J. Gastroenterol., 46, 1401-1403.

Andre, T., Tournigand, C., Rosmorduc, O., Provent, S., MaindraultGoebel, F., Avenin, D., Selle, F., Paye, F., Hannoun, L., Houry, S., Gayet, B., Lotz, J.P., de Gramont, A. \& Louvet, C. (2004) Gemcitabine combined with oxaliplatin (GEMOX) in advanced biliary tract adenocarcinoma: a GERCOR study. Ann. Oncol., 15, 1339-1343.

Carter, J.T., Grenert, J.P., Rubenstein, L., Stewart, L. \& Way, L.W. (2008) Tumors of the ampulla of vater: histopathologic classification and predictors of survival. J. Am. Coll. Surg., 207, 210-218

Cassidy, J., Tabernero, J., Twelves, C., Brunet, R., Butts, C., Conroy, T., Debraud, F., Figer, A., Grossmann, J., Sawada, N., Schoffski, P., Sobrero, A., Van Cutsem, E. \& Diaz-Rubio, E. (2004) XELOX (capecitabine plus oxaliplatin): active firstline therapy for patients with metastatic colorectal cancer. $J$. Clin. Oncol., 22, 2084-2091.

Cereda, S., Passoni, P., Reni, M., Vigano, M.G., Aldrighetti, L., Nicoletti, R. \& Villa, E. (2010) The cisplatin, epirubicin, 5 -fluorouracil, gemcitabine (PEFG) regimen in advanced biliary tract adenocarcinoma. Cancer, 116, 2208-2214.

Chu, P.G., Schwarz, R.E., Lau, S.K., Yen, Y. \& Weiss, L.M. (2005) Immunohistochemical staining in the diagnosis of pancreatobiliary and ampulla of Vater adenocarcinoma: application of CDX2, CK17, MUC1, and MUC2. Am. J. Surg. Pathol., 29, 359-367.

Cunningham, D., Atkin, W., Lenz, H.J., Lynch, H.T., Minsky, B., Nordlinger, B. \& Starling, N. (2010) Colorectal cancer. Lancet, 375, 1030-1047.

de Castro, S.M., van Heek, N.T., Kuhlmann, K.F., Busch, O.R., Offerhaus, G.J., van Gulik, T.M., Obertop, H. \& Gouma, D.J. (2004) Surgical management of neoplasms of the ampulla of Vater: local resection or pancreatoduodenectomy and prognostic factors for survival. Surgery, 136, 994-1002.

Fischer, H.P. \& Zhou, H. (2004) Pathogenesis of carcinoma of the papilla of Vater. J. Hepatobiliary Pancreat. Surg., 11, 301-309.

Gibson, M.K., Holcroft, C.A., Kvols, L.K. \& Haller, D. (2005) Phase II study of 5-fluorouracil, doxorubicin, and mitomycin C for metastatic small bowel adenocarcinoma. Oncologist, 10, 132-137.

Hansel, D.E., Maitra, A., Lin, J.W., Goggins, M., Argani, P., Yeo, C.J., Piantadosi, S., Leach, S.D. \& Biankin, A.V. (2005) Expression of the caudal-type homeodomain transcription factors CDX 1/2 and outcome in carcinomas of the ampulla of Vater. J. Clin. Oncol., 23, 1811-1818.

Heinrich, S. \& Clavien, P.A. (2010) Ampullary cancer. Curr. Opin. Gastroenterol., 26, 280-285.

Howe, J.R., Klimstra, D.S., Cordon-Cardo, C., Paty, P.B., Park, P.Y. \& Brennan, M.F. (1997) K-ras mutation in adenomas and 
carcinomas of the ampulla of vater. Clin. Cancer Res., $\mathbf{3}$, 129-133.

Howe, J.R., Klimstra, D.S., Moccia, R.D., Conlon, K.C. \& Brennan, M.F. (1998) Factors predictive of survival in ampullary carcinoma. Ann. Surg., 228, 87-94.

Jatoi, A., Murphy, B.R., Foster, N.R., Nikcevich, D.A., Alberts, S.R., Knost, J.A., Fitch, T.R. \& Rowland, K.M. Jr. (2006) Oxaliplatin and capecitabine in patients with metastatic adenocarcinoma of the esophagus, gastroesophageal junction and gastric cardia: a phase II study from the North Central Cancer Treatment Group. Ann. Oncol., 17, 29-34.

Kim, G.M., Jeung, H.C., Rha, S.Y., Kim, H.S., Jung, I., Nam, B.H., Lee, K.H. \& Chung, H.C. (2012) A randomized phase II trial of S-1-oxaliplatin versus capecitabine-oxaliplatin in advanced gastric cancer. Eur. J. Cancer, 48, 518-526.

Kim, S.T., Lee, J., Lee, K.T., Lee, J.K., Lee, K.H., Choi, S.H., Heo, J.S., Choi, D.W., Park, S.H., Park, J.O., Lim, H.Y., Park, Y.S. \& Kang, W.K. (2010) The efficacy of frontline platinumbased combination chemotherapy in advanced adenocarcinoma of the ampulla of Vater. Med. Oncol., 27, 1149-1154.

Kimura, W., Futakawa, N., Yamagata, S., Wada, Y., Kuroda, A., Muto, T. \& Esaki, Y. (1994) Different clinicopathologic findings in two histologic types of carcinoma of papilla of Vater. Jpn. J. Cancer Res., 85, 161-166.

Lee, J., Park, S.H., Chang, H.M., Kim, J.S., Choi, H.J., Lee, M.A., Jang, J.S., Jeung, H.C., Kang, J.H., Lee, H.W., Shin, D.B., Kang, H.J., Sun, J.M., Park, J.O., Park, Y.S., Kang, W.K. \& Lim, H.Y. (2012) Gemcitabine and oxaliplatin with or without erlotinib in advanced biliary-tract cancer: a multicentre, openlabel, randomised, phase 3 study. Lancet Oncol., 13, 181-188.

Lowe, M.C., Coban, I., Adsay, N.V., Sarmiento, J.M., Chu, C.K., Staley, C.A., Galloway, J.R. \& Kooby, D.A. (2009) Important prognostic factors in adenocarcinoma of the ampulla of Vater. Am. Surg., 75, 754-760; discussion 761.

Monson, J.R., Donohue, J.H., McEntee, G.P., McIlrath, D.C., van Heerden, J.A., Shorter, R.G., Nagorney, D.M. \& Ilstrup, D.M. (1991) Radical resection for carcinoma of the ampulla of Vater. Arch. Surg., 126, 353-357.

Overman, M.J., Varadhachary, G.R., Kopetz, S., Adinin, R., Lin, E., Morris, J.S., Eng, C., Abbruzzese, J.L. \& Wolff, R.A. (2009) Phase II study of capecitabine and oxaliplatin for advanced adenocarcinoma of the small bowel and ampulla of Vater. $J$. Clin. Oncol., 27, 2598-2603.

Perrone, G., Santini, D., Zagami, M., Vincenzi, B., Verzi, A., Morini, S., Borzomati, D., Coppola, R., Antinori, A., Magistrelli, P., Tonini, G. \& Rabitti, C. (2006) COX-2 expression of ampullary carcinoma: correlation with different histotypes and clinicopathological parameters. Virchows Arch., 449, 334-340.

Rao, S., Cunningham, D., Hawkins, R.E., Hill, M.E., Smith, D., Daniel, F., Ross, P.J., Oates, J. \& Norman, A.R. (2005) Phase III study of 5FU, etoposide and leucovorin (FELV) compared to epirubicin, cisplatin and 5FU (ECF) in previously untreated patients with advanced biliary cancer. Br. J. Cancer, 92, 16501654.

Romiti, A., Barucca, V., Zullo, A., Sarcina, I., Di Rocco, R., D'Antonio, C., Latorre, M. \& Marchetti, P. (2012) Tumors of ampulla of Vater: a case series and review of chemotherapy options. World J. Gastrointest. Oncol., 4, 60-67.

Ruemmele, P., Dietmaier, W., Terracciano, L., Tornillo, L., Bataille, F., Kaiser, A., Wuensch, P.H., Heinmoeller, E., Homayounfar, K., Luettges, J., Kloeppel, G., Sessa, F., Edmonston, T.B., Schneider-Stock, R., Klinkhammer-Schalke, M., Pauer, A., Schick, S., Hofstaedter, F., Baumhoer, D. \& Hartmann, A. (2009) Histopathologic features and microsatellite instability of cancers of the papilla of vater and their precursor lesions. Am. J. Surg. Pathol., 33, 691-704.

Saltz, L.B., Clarke, S., Diaz-Rubio, E., Scheithauer, W., Figer, A., Wong, R., Koski, S., Lichinitser, M., Yang, T.S., Rivera, F., Couture, F., Sirzen, F. \& Cassidy, J. (2008) Bevacizumab in combination with oxaliplatin-based chemotherapy as first-line therapy in metastatic colorectal cancer: a randomized phase III study. J. Clin. Oncol., 26, 2013-2019.

Sessa, F., Furlan, D., Zampatti, C., Carnevali, I., Franzi, F. \& Capella, C. (2007) Prognostic factors for ampullary adenocarcinomas: tumor stage, tumor histology, tumor location, immunohistochemistry and microsatellite instability. Virchows Arch., 451, 649-657.

Valle, J., Wasan, H., Palmer, D.H., Cunningham, D., Anthoney, A., Maraveyas, A., Madhusudan, S., Iveson, T., Hughes, S., Pereira, S.P., Roughton, M. \& Bridgewater, J. (2010) Cisplatin plus gemcitabine versus gemcitabine for biliary tract cancer. N. Engl. J. Med., 362, 1273-1281.

Westgaard, A., Pomianowska, E., Clausen, O.P. \& Gladhaug, I.P. (2013) Intestinal-type and pancreatobiliary-type adenocarcinomas: how does ampullary carcinoma differ from other periampullary malignancies? Ann. Surg. Oncol., 20, 430-439.

Westgaard, A., Schjolberg, A.R., Cvancarova, M., Eide, T.J., Clausen, O.P. \& Gladhaug, I.P. (2009) Differentiation markers in pancreatic head adenocarcinomas: MUC1 and MUC4 expression indicates poor prognosis in pancreatobiliary differentiated tumours. Histopathology, 54, 337-347.

Westgaard, A., Tafjord, S., Farstad, I.N., Cvancarova, M., Eide, T.J., Mathisen, O., Clausen, O.P. \& Gladhaug, I.P. (2008) Pancreatobiliary versus intestinal histologic type of differentiation is an independent prognostic factor in resected periampullary adenocarcinoma. BMC Cancer, 8, 170.

Woo, S.M., Ryu, J.K., Lee, S.H., Yoo, J.W., Park, J.K., Kim, Y.T., Jang, J.Y., Kim, S.W., Kang, G.H. \& Yoon, Y.B. (2007) Recurrence and prognostic factors of ampullary carcinoma after radical resection: comparison with distal extrahepatic cholangiocarcinoma. Ann. Surg. Oncol., 14, 3195-3201.

Zhou, H., Schaefer, N., Wolff, M. \& Fischer, H.P. (2004) Carcinoma of the ampulla of Vater: comparative histologic/immunohistochemical classification and follow-up. Am. J. Surg. Pathol., 28, 875-882. 